\title{
O Programa Municípios Verdes sob a luz da legislação ambiental
}

\author{
Raissa Jennifer da Silva de Sáa , Samya de Freitas Moreiraa , Mário Marcos Moreira da Conceiçãoa, \\ Milla Cristina Santos da Cruz ${ }^{a}$, Antônio Pereira Júniora iD \\ aUniversidade do Estado do Pará (UEPA) - Campus VI, Paragominas, PA, Brasil.
}

RESUMO O Programa Municípios Verdes, do Estado do Pará, surgiu como uma ferramenta para implantar o "pacto de desenvolvimento sustentável" entre os municípios considerados críticos. O objetivo deste estudo foi a realização de uma análise quantiqualitativa, com método dedutivo, de natureza aplicada e procedimentos observativos sobre o Programa Municípios Verdes. Os dados obtidos e analisados indicaram que, desde a criação, em março de 2011, até o final de 2012, ocorreu uma tendência a redução em $27 \%$ sobre o desmatamento, e uma tendência a elevação, equivalente a $51 \%$, no número de propriedades inseridas no Cadastro Ambiental Rural. Logo, os desafios para a construção de um município que se enquadre no título "Município Verde", para que seja inclusivo e próspero, requerem esforços continuados de longo prazo, com diálogos e celebração de parcerias entre os diferentes setores da sociedade, desde que cumpram as diretrizes da legislação ambiental vigente contidas nesse plano.

PALAVRAS-CHAVE: desmatamento; pacto de desenvolvimento sustentável; programa de ação

Recebido 12 de dezembro de 2018 Aceito 22 de dezembro de 2018 Publicado online 02 de janeiro de 2019

Cite este artigo: Sá RJS et al. (2019) O Programa Municípios Verdes sob a luz da legislação ambiental. Multidisciplinary Reviews 2: e2019003, DOI: 10.29327/multi.2019003

\section{The Programa Municípios Verdes under the environmental legislation}

ABSTRACT The Programa Municípios Verdes, in the State of Pará (Brazil), emerged as a tool to implement the "sustainable development pact" among municipalities considered critical. The objective of this study was the accomplishment of a quantity and qualitative analysis, with the deductive method, of applied nature and observational procedures on the Programa Municípios Verdes. The data obtained and analyzed indicated that, from the creation in March 2011, until the end of 2012, there was a tendency to reduce by $27 \%$ on deforestation, and a tendency to increase, equivalent to $51 \%$, the number of properties inserted in the Rural Environmental Registry. In order to be inclusive and prosperous, the challenges for the construction of a municipality that falls under the title "Green Municipality" require continuous long-term efforts, with dialogues and the celebration of partnerships between different sectors of society, if they fulfill the current environmental legislation contained in this plan.

KEYWORDS: action plan; deforestation; sustainable development pact

\section{Introdução}

Com o aumento desordenado de desastres ambientais em municípios da Amazônia Legal, a implantação de políticas públicas começa a criar força em prol do desenvolvimento sustentável. Neste contexto, surgiram iniciativas locais ou regionais de combate ao desmatamento, como é o caso do Programa Municípios Verdes, no Estado do Pará (Rivero et al 2009).

O Programa Municípios Verdes foi inspirado na experiência bem-sucedida do município paraense de Paragominas que, após ter sua história associada à expansão de atividades econômicas que incentivavam desmatamento, lançou no começo de 2008 o “Paragominas - Município Verde”, projeto bem-sucedido que teve objetivo de enfrentar os altos índices de desmatamento a partir da realização de um pacto local (Castello et al 2017).

Três anos após a criação, ou seja, em 2011, o programa consolidou-se pelo Governo do Pará, cujo principal objetivo foi combater o desmatamento e fortalecer a produção rural sustentável por meio de ações estratégicas de ordenamento ambiental e fundiário. O município que aderir ao programa se compromete a cumprir um conjunto de 
metas, a serem monitoradas e validadas, e passa a estar habilitado para receber benefícios como o desembargo ambiental, incentivos fiscais e a ter prioridade na alocação dos recursos públicos estaduais (Costa e Fleury 2015).

Para auxiliar os municípios a cumprirem as metas exigidas do Programa Municípios Verdes, buscou-se viabilizar ações que contribuam efetivamente para o fortalecimento e estruturação dos sistemas municipais de meio ambiente. Dentre as ações municipais, um conjunto de leis de meio ambiente (Ex.: as Portarias 01, 04 e 08 de 2013 ) que regulamentam as metas gerais do Programa Municípios Verdes devem ser incorporadas nas práticas municipais (Whately e Campanili 2013).

Ademais, a primeira dispõe sobre a constituição de grupo de trabalho do Cadastro Ambiental Rural - CAR (Pará 2013a); a segunda dispõe sobre a criação do grupo para revisão dos critérios da lista federal do desflorestamento (Pará 2013b), e a terceira trata sobre a criação de um grupo de trabalho de apoio às ações de combate e prevenção ao desmatamento (Pará 2013c).

Consequentemente, o cumprimento das leis ambientais reduz a possibilidade de sanções como multas ou embargos econômicos; a atração de investidores, pois, ser um "Município Verde" é um diferencial de mercado e torna atrativa a chegada e permanência de bons investidores, além de incentivos creditícios, à medida que a nova visão dos municípios em relação às questões ambientais e sociais pode criar as condições necessárias para acesso ao crédito, fomento e assistência técnica rural, e o desembargo e regularização das propriedades rurais (Cesfgv 2016).

Neste contexto, o Programa Municípios Verdes, expressa-se em um espaço economicamente desvalorizado, mas, se revaloriza após a incorporação de políticas ambientais, as quais necessitam ser estudadas, o que justifica essa pesquisa, cuja a relevância é incrementada pela elaboração de informações que cooperam para a sensibilização em relação a problemática das questões ambientais. E por fim, alcançar o objetivo, que é uma análise das legislações que dão suporte as metas gerais do Programa Municípios Verdes, a fim de evidenciar a incorporação de mecanismos legais como um fator determinante para garantir a preservação do equilíbrio ambiental.

\section{Um modelo de inspiração para o programa município verde}

Curitiba já foi reconhecida nacional e internacionalmente por seu planejamento urbano, por suas ideias inovadoras relacionadas à mobilidade urbana, e como percursora na proposição de políticas públicas ambientais. Apesar de todas essas conquistas, como qualquer outra grande metrópole brasileira, Curitiba sofre as mesmas pressões e perda de áreas naturais por conta do processo de urbanização que, muitas vezes, ocorre em áreas que abrigam renascentes florestais importantes para a manutenção da biodiversidade e da qualidade de vida dos seus habitantes (Arashiro 2016).

Medidas preventivas devem ser elaboradas no sentido de permitir o desenvolvimento urbano e ao mesmo tempo preservar os ecossistemas locais. Por isso a Prefeitura de Curitiba busca atingir este equilíbrio a partir de uma Política de Meio Ambiente adotada desde a década de 70, que resultou na criação de legislações ambientais; implementação de programas de Educação Ambiental como o programa "Lixo que não é Lixo"; criação de Unidades de Conservação, e a incrementação da arborização pública (Censi 2010).

Em 2006, uma importante ação relacionada à conservação foi implantada pela Prefeitura de Curitiba. Concebeuse o Programa de Biodiversidade Urbana (BIOCIDADE) que visa reduzir as perdas da biodiversidade no ambiente urbano, ao compatibilizar desenvolvimento e conservação ambiental. O projeto busca a identificação e estudo de espécies da flora nativa com potencial paisagístico, a possibilidade de sua produção e utilização no paisagismo de áreas como parques, praças e jardins públicos, jardins privados e quintais (Panasolo et al 2014).

Para buscar uma amplitude ainda maior, o Biocidade, no conceito mais amplo, aglutina ações que se desenvolvem de forma isolada no universo da Administração Municipal, ao identificar o potencial para consolidar o Programa de Biodiversidade Urbana que difunde um novo modelo de preservação ambiental (Grise et al 2016).

\section{Origem do Programa Municípios Verdes}

O processo de ocupação e desenvolvimento da Amazônia, concebido na segunda metade do século anterior, marcado pela construção de rodovias e implantação de grandes projetos de energia, mineração e agropecuária, 
resultou, na verdade, em pouca geração de riqueza e qualidade de vida para os habitantes da região (Castello et al 2017). Por outro lado, esse processo ocasionou graves impactos ambientais, cuja face mais visível é o desmatamento e a degradação da Floresta Amazônica. Até 2012, o desmatamento havia atingido quase 19\% da floresta original do território e estima-se que uma área similar tenha sido degradada pela extração de madeira e/ou fogo (Rivero et al 2009 ).

O Plano de Ação para Prevenção e Controle do Desmatamento na Amazônia Legal (PPCDAM), obteve a importância estratégia da Amazônica e em resposta às pressões da opinião pública brasileira e internacional, o governo do Brasil lançou em 2004, esse ambicioso programa que buscava combater o desmatamento e criava as condições para o estabelecimento de um modelo de desenvolvimento sustentável na Amazônia Legal (Alves 2010).

Na primeira fase (2004-2007), esse programa resultou na criação de cerca de $480.000 \mathrm{~km}^{2}$ de Unidades de Conservação, o que elevou a proporção de áreas protegidas de $28 \%$ para $38 \%$ nessa Amazônia. Houve também avanços significativos na área de comando e controle, com destaque para aumento da fiscalização de campo, prisão de autoridades e produtores envolvidos com o desmatamento ilegal e o lançamento dos sistemas de monitoramento com imagens de satélite em tempo real, como o Sistema de Alerta de Desmatamento (SAD) e Detecção de Desmatamento em tempo real (DETER) (Carneiro e Assis 2015).

Esse conjunto de medidas reduziu o desmatamento de $19.600 \mathrm{~km}^{2}$ a 6,3×103 km2 (Figura 01). Isso representou uma queda de cerca de $80 \%$ entre a taxa de desmatamento registrada em 2004 (início do PPCDAM) e a de 2012 (Costa e Fleury 2015).

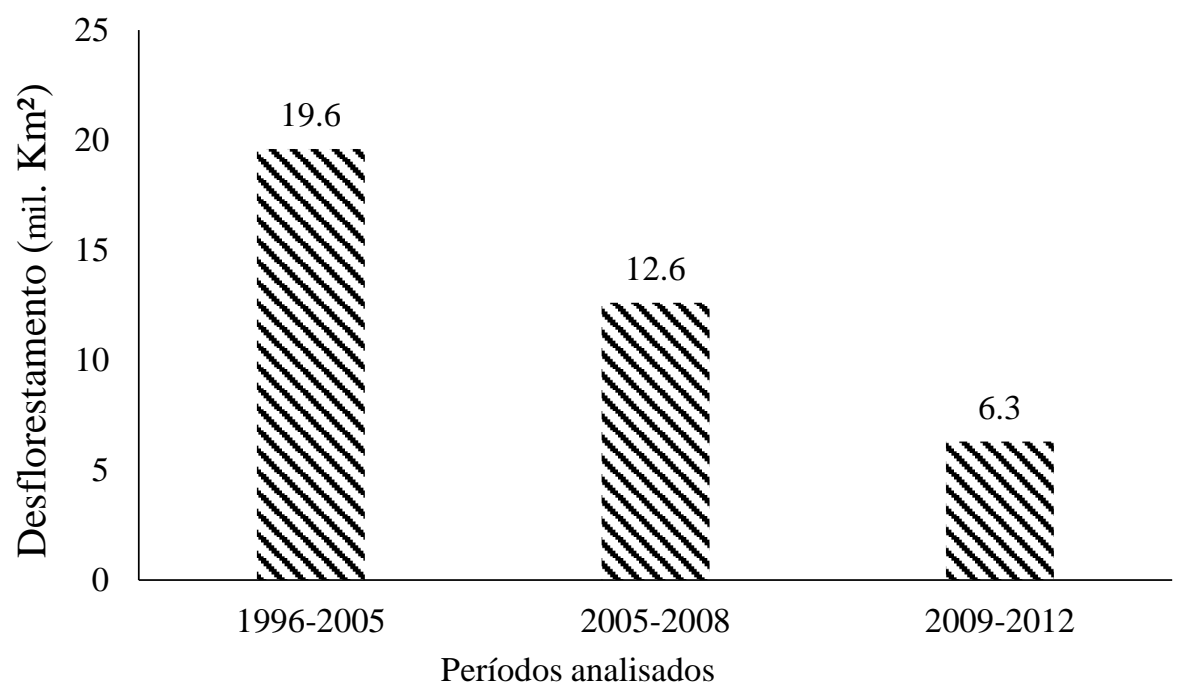

Figura 1 Desflorestamento nos períodos de 1996 a 2012. Fonte: adaptado de Guimarães et al (2013).

O que possibilitou a queda expressiva do desmatamento, sobretudo a partir de 2008 , foi a inovação na estratégia de enfrentamento do problema, dentre elas: a restrição do crédito rural para projetos agropecuários no Bioma Amazônico; a lista de municípios que mais desmatam na Amazônia; imposição de diversas restrições administrativas; a lista de áreas embargadas para os imóveis rurais em decorrência do desmatamento; responsabilização da cadeia produtiva da carne, bem como de todos os agentes dessa cadeia que adquirissem produtos de áreas embargadas, e o fortalecimento das operações de fiscalização que ficaram mais efetivas e constantes (Santos et al 2016).

Consequentemente, existe grande preocupação quanto à suficiência dessas medidas para erradicar ou mesmo controlar o desmatamento ilegal a longo prazo. Foi nesse contexto que surgiram iniciativas locais ou regionais de combate ao desmatamento com potencial enorme de sustentar e aprofundar os ganhos até então obtidos, como é o caso do Programa Municípios Verdes, no Estado do Pará (Merlin e Oliveira 2015). 


\title{
Quanto ao Decreto Estadual n. 54:2011
}

O Programa Municípios Verdes foi pensado como ferramenta para auxiliar os municípios que compunham a lista dos maiores desmatadores da Amazônia, divulgada pelo Ministério do Meio Ambiente (MMA) em 2008. O objetivo era criar um "pacto de desenvolvimento sustentável" entre os municípios considerados críticos ao longo do corredor da exploração madeireira e do desmatamento, o chamado "arco do desmatamento" (Macedo 2013). Lançado em março de 2011 pelo Governo Federal, o Programa Municípios Verdes foi criado pelo Decreto Estadual n. 54:2011 (Pará 2011), o qual dispõe, no art. $1^{\text {a: }}$

Fica instituído o Programa de Municípios Verdes destinado a dinamizar a economia local em bases sustentáveis por meio de estímulos para que os municípios paraenses melhorem a governança pública municipal, promovam segurança jurídica, atraiam novos investimentos, reduzam desmatamento e degradação, e promovam a recuperação ambiental e a conservação dos recursos naturais (Pará, 2011, p.1).

O programa conta com a parceria de cerca 21 instituições públicas, privadas e da sociedade civil organizada, tal como disposto no art. $2 \stackrel{\circ}{\circ}$ :

\begin{abstract}
Será implementado por meio de parceria interinstitucional com entidades públicas, privadas e nãogovernamentais, consoante os termos de cooperação específicos firmados com o Estado do Pará, por meio da Coordenação do Programa Municípios Verdes (Pará, 2011, p.1).
\end{abstract}

Quanto aos objetivos gerais, o Decreto Estadual n. 54:2011, dispõe os seguintes: i) reduzir gradativamente o desmatamento, ao buscar, a partir de 2020, um desmatamento líquido de zero; ii) retirar Municípios da lista "crítica de desmatamento" do Ministério do Meio Ambiente; iii) aumentar a adesão de imóveis rurais ao Cadastro Ambiental Rural; iv) engajar os Municípios no cumprimento de tais metas (Guimarães et al 2013).

Neste contexto, o Programa foi inspirado na experiência bem-sucedida do município de Paragominas que, em 2008, lançou o projeto Paragominas - Município Verde, onde enfrentava a questão do desmatamento a partir de um pacto com a sociedade local e com diversas ações empreendidas por parceiros atuantes no município (prefeitura, sindicatos dos produtores rurais, ONGs, trabalhadores, Ministério Público Federal, dentre outros). A iniciativa foi exitosa, de tal forma que, em 2010, Paragominas foi o primeiro município da Amazônia a sair da lista do desmatamento (Oliveira et al 2012).

\section{Quanto às portarias envolvidas}

Para a coordenação do Programa Municípios Verdes, destaca-se as seguintes Portarias:

- Portaria n. 08:2013 - Programa Municípios Verdes, de 27 de junho de 2013, dispõe sobre a constituição de Grupo de Trabalho de apoio às ações de combate e prevenção do desmatamento ilegal e ao Desenvolvimento Sustentável de Projetos de Assentamentos Federais e Estaduais do Pará (Pará 2013c).

Art. 1을 Criar Grupo de Trabalho de apoio às ações de combate e prevenção do desmatamento ilegal e ao Desenvolvimento Sustentável, além de contribuir com a construção de políticas públicas para a promoção de alternativas de regularização ambiental e fundiária em Projetos de Assentamentos Federais e Estaduais do Pará (Pará, 2013, p. 2).

- Portaria n. 04:2013 - Programa Municípios Verdes, de 22 de fevereiro de 2013, dispõe sobre a constituição de Grupo de Trabalho para revisão dos critérios da lista federal do desmatamento (Pará 2013b), no art. 10 Criar Grupo de Trabalho para revisão e proposição de novos critérios de entrada e saída dos municípios da lista federal do desmatamento. 
- Portaria n. 01:2013 - Programa Municípios Verdes, de 22 de fevereiro de 2013, dispõe sobre a Constituição de Grupo de Trabalho do Cadastro Ambiental Rural - CAR (Pará 2013a).

Art. $1^{\circ}$ Criar Grupo de Trabalho do Cadastro Ambiental Rural, denominado GT do CAR, com a finalidade de apoiar a identificação de barreiras e a proposição de soluções para o aperfeiçoamento do CAR buscando a sua consolidação como ferramenta para o ordenamento territorial e ambiental no estado do Pará (Pará, 2013, p.12).

\section{Quanto aos efeitos da legislação ambiental}

Em fevereiro de 2013, o Programa Municípios Verdes promoveu um encontro técnico com seus parceiros, a fim de definir quais os critérios para enquadramento na categoria "Municípios Verdes" e quais os níveis poderiam ser alcançados. Isso porque existe grande preocupação em zelar pela marca do programa, bem como evitar que os municípios recebam tal designação quando ainda não tiverem definitivamente controlado o desmatamento e concluído o processo de regularização ambiental. Diante disso, propõe-se a criação de três níveis para a categoria "Municípios Verdes" (Merlin e Oliveira 2016).

As metas gerais (Figura 02), contidas no Programa Municípios Verdes, assim como o caráter legislativo ambiental para a regulamentação de cada aspecto, devem ser objetos de estudo pelos municípios candidatos ao programa, para que possam fomentar recursos com o objetivo de alcançar essas metas.

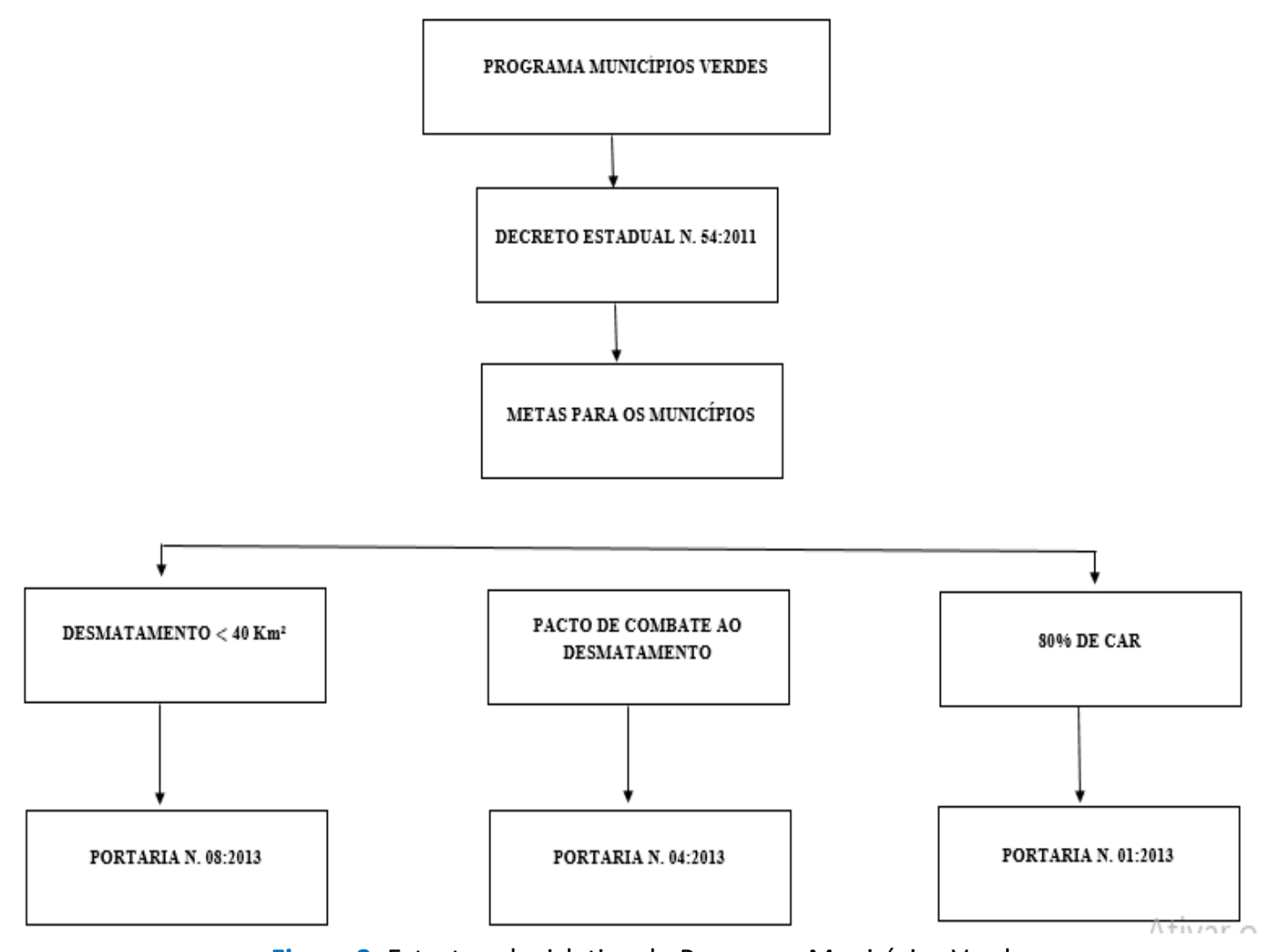

Figura 2. Estrutura legislativa do Programa Municípios Verdes.

Conforme a Portaria n. 08:2013 do PMV (Pará 2013c), o município precisa reduzir o desmatamento para menos de 40 quilômetros quadrados por ano e ter uma taxa média dos dois últimos anos menor ou igual a $60 \%$ do ocorrido entre 2005 e 2008. Entretanto, o ideal é zerar o desmatamento ou trabalhar com números próximos a zero (Macedo 2013). 
Os principais benefícios da redução do desmatamento são em número de três: (1) a saída ou não inclusão na lista de prioritários no combate ao desmatamento; oportunidade de negócios, pois melhora a imagem do município e de quem produz no local, o que pode atrair investidores; (2) redução de emissões de Gases de Efeito Estufa (GEE); (3) diminuição dos gastos com saúde, pois as fumaças e as cinzas provenientes de incêndios florestais e queimadas podem provocar doenças respiratórias e até mortes, além da redução da perda de biodiversidade (Rivero et al 2009).

O MMA divulgou, em 27 de novembro de 2012, as estimativas sobre o desmatamento na Amazônia Legal para o período 2011/2012. Foi verificado $4.656 \mathrm{~km}^{2}$ de desmatamento, o que representa o menor índice desde o início da medição feita pelo Instituto Nacional de Pesquisas Espaciais (INPE), em 1988. Em comparação ao período anterior, houve uma redução de $27 \%$ do desmatamento (Oliveira et al 2012).

Os dados absolutos demonstram que dos nove estados integrantes da Amazônia Legal, o Pará teve o melhor resultado, com uma redução no desmatamento de $1.309 \mathrm{~km}^{2}$, o que colaborou com $74,2 \%$ da redução do desmatamento em toda Amazônia. Em termos proporcionais, o Pará teve uma redução de $44 \%$ no desmatamento se comparado ao ano anterior. A participação do estado no desmatamento total da Amazônia caiu de 57\%, em 2009, para 36\%, em 2012 (Guimarães et al 2013).

Em relação a Portaria n. 04:2013 (Pará 2013b) que regulamenta uma série de medidas como o pacto de combate ao desmatamento e a revisão de novos critérios de entrada e saída dos municípios da lista federal do desmatamento, foi adotada como plano de ação de prevenção, monitoramento e controle do desmatamento legal. Observou-se que houve uma significativa melhoria à medida que surgia a necessidade de recuperar áreas degradadas que, dentre outros efeitos, restringiu o acesso dos produtores do município ao crédito bancário oficial (Costa e Fleury 2015).

Esse crédito é um benefício concebido pelo Conselho Monetário Nacional aos produtores rurais. Com o pacto de combate ao desmatamento, o produtor que fizer parte desse acordo, irá adquirir um requerimento de regularização fundiária, enquanto que para os demais municípios do bioma amazônico, para ter acesso a recursos do crédito bancário, precisam apresentar, obrigatoriamente, o Certificado de Cadastro de Imóvel Rural (CCIR), fornecido pelo Instituto Nacional de Colonização e Reforma Agrária (INCRA) (Carneiro e Assis 2015).

Essa Portaria representa a passagem de uma agenda de trabalho com características negativas como o desmatamento descontrolado e descentralizado, para outra, de características mais positivas, na qual os produtores rurais e o município passariam a obter benefícios, com o estabelecimento do compromisso para a não realização de novos desmatamentos no município (Alves 2010).

Quanto a Portaria n. 01:2013 (Pará 2013a), esta regulamenta o Cadastro Ambiental Rural (CAR) como estratégia para construir paisagens produtivas sustentáveis. O Cadastro Ambiental Rural tornou-se indispensável para o licenciamento ambiental de uma propriedade, e por isso ele é o principal requisito para o ingresso dos municípios no programa, ao exigir inclusão no de pelo menos $80 \%$ dos imóveis rurais (Guimarães et al 2013).

O CAR é composto de mapa georreferenciado e diagnóstico ambiental. No mapa, devem ser indicadas as áreas de preservação permanente, de Reserva Legal e remanescentes de vegetação nativa localizados no interior do imóvel para fins de controle e monitoramento. Além da obrigatoriedade legal, o Programa Municípios Verdes considera o CAR um instrumento fundamental para o ordenamento territorial do município, pelo qual é possível identificar não apenas os passivos, mas também os ativos ambientais (Santos et al 2016).

Para acelerar o CAR, o governo do Pará fez uma parceria com o Governo da Noruega, o Ministério do Meio Ambiente e o Programa das Nações Unidades para o Desenvolvimento (PNUD) com o objetivo de fornecer os meios técnicos necessários para a sua realização e, assim, aumentar a área cadastrada (Castello 2017).

Os dois primeiros municípios contemplados pelo novo convênio foram Ulianópolis e Dom Eliseu, ambos no estado do Pará, que tiveram o cadastro feito no tempo recorde de dez meses (fevereiro a dezembro de 2012). Paragominas, no mesmo estado, já havia providenciado o cadastramento antes da assinatura do referido acordo. Em 2012, o Pará contava com cerca de metade da área cadastrável inserida no CAR, que correspondia a 31,33 milhões de hectares distribuídos em 62.750 mil imóveis, o que significou um aumento de $51 \%$ em área em relação ao existente em 2011 (Oliveira et al 2012). Dos 144 municípios do estado do Pará, 107 já tiveram sua adesão consolidada ao programa, superando a meta de atingir 100 municípios em 2015 (Alves 2010). 


\section{Considerações finais}

O Programa Municípios Verdes, considerado aqui como um programa de ação, aparece como proposta de recuperação dessas áreas degradadas. Dessa forma, para que os municípios obtenham o título de "município verde", eles devem seguir os objetivos de quatro legislação que regulamentam as metas gerais do Programa. A legislação que instituiu o programa foi o Decreto Estadual n. 54:2011, que dentre os objetivos, o principal dispõe que os municípios devem reduzir gradativamente o desmatamento e engajar os Munícipios no cumprimento de tais metas.

Para que as metas sejam atingidas destacaram-se as seguintes portarias, no qual são necessárias para a coordenação do programa, sendo elas a Portaria n. 08:2013; Portaria n. 04:2013 e Portaria n. 01:2013, que dispõe em forma geral sobre a constituição de Grupos de Trabalho para o combate e prevenção do desmatamento ilegal, para revisão dos critérios da lista federal do desmatamento e para o CAR.

Em suma, o Pará e a Amazônia representam uma grande oportunidade para mostrar ao mundo que é possível conciliar conservação dos recursos naturais e produção rural sustentável como demonstra o Programa Municípios Verdes. Demonstra-se também que os desafios de construir um município que se enquadra no título "Município Verde", inclusivo e próspero são permanentes e por isso requerem esforços continuados de longo prazo e disposição verdadeira de diálogo e parceria entre os diferentes setores da sociedade, cumprindo as diretrizes da legislação ambiental vigente.

\section{Referências}

Alves DS (2010) O processo de desmatamento na Amazônia. Revista Parcerias estratégicas 6:259-275.

Arashiro P (2016) Planos diretores de Curitiba e aplicações da Biocidade: propostas para um urbanismo sustentável. Revista Ambiente e Sociedade 12:25-45.

Carneiro MS, Assis WS (2015) O controle do desmatamento na Amazônia como um processo de modernização ecológica: a experiência do Projeto Município Verde. Revista Pós Ciências Sociais 12:53-76.

Castello RN, Vidal JP, Begot LH, Faria TLM, Nunes SF (2017) Gestão Ambiental no Pará: o Programa Municípios Verdes no município de Abaetetuba. Revista Espacios 38:1-18.

Censi DR (2010) Conflitos socioambientais urbano-metropolitanos: cidadania, sustentabilidade e gestão no contexto da RMC-Região Metropolitana de Curitiba. Revista Ambiente e Sociedade 18:67-81.

Costa JM, Fleury MF (2015) O Programa "Municípios Verdes": estratégias de revalorização do espaço em municípios paraenses. Revista Ambiente e Sociedade 18 61-76.

Guimarães J, Veríssimo A, Amaral P, Pinto A, Demachko A (2013) Municípios Verdes: caminhos para a sustentabilidade. Imazon, Belém.

Grise MM, Biondi D, Araki H (2016) A Floresta Urbana da Cidade de Curitiba. Revista Floresta 46:425-438.

CESFGV (2016) Centro de Estudos em Sustentabilidade da Fundação Getúlio Vargas. Planejamento e Ordenamento territorial. Ordenamento territorial. Bibliotecadigital.fgv.br. Acesso em: 12 dezembro 2018.

MACEDO LSV (2013) O Fundo Amazônia em apoio à ação local pela Redução do Desmatamento no Pará: O Projeto IMAZON para Municípios Verdes. Fundo Amazônia 1-19.

Merlin LVCT, Oliveira AC (2016) ICMS verde para a redução do desmatamento amazônico: estudo sobre uma experiência recente. Revista Veredas do Direito 13:277-306.

Oliveira RS, Gomes SC, Cabral ER (2012) Da condição de município "Marrom" a município "Verde": o caso de Paragominas - PA. Revista de Administração e Negócios da Amazônia 4:122-139.

Panasolo A, Silva JCGL, Peters EL, Santos AJ (2014) Áreas verdes urbanas privadas de Curitiba: uma proposta de valorização para conservação (estudo de caso). Enciclopédia Biosfera 10:2731-2744.

Pará. Programa de Municípios Verdes (2011) Decreto n. 54. www.semas.pa.gob.br. Acesso em 12 dezembro 2018.

Pará. Constituição Estadual (2013a) Portaria n. 01. www.cee.pa.gov.br. Acesso em 12 dezembro 2018.

Pará. Constituição Estadual (2013b) Portaria n. 04. www.cee.pa.gov.br. Acesso em 12 dezembro 2018. 
Pará. Constituição Estadual (2013c) Portaria n. 08. www.cee.pa.gov.br. Acesso em 12 dezembro 2018.

Rivero S, Almeida O, Ávila S, Oliveira W (2009) Pecuária e desmatamento: uma análise das principais causas diretas do desmatamento na Amazônia. Revista Nova economia 19:41-66.

Santos PFA, Almeida NA, Lacerda LPT, Silva SM, Brito RA (2016) Os Impactos do Programa Municípios Verdes (PMV) no Controle do Desmatamento da Amazônia: uma análise usando propensity score matching. Revista Economia Ensaios 30:23-74.

Whately, M, Campanili M. (2013) Programa municípios verdes: lições aprendidas e desafios 2013/2014. Governo do Estado do Pará. Programa Municípios Verdes. Disponível em: www.municipiosverdes.pa.gov.br. Acesso em 12 dezembro 2018. 